\title{
Determination of Maintenance Task on Rotary Equipment Using Reliability Centered Maintenance II Method
}

\author{
Dwi Priyanta ${ }^{1}$, Nurhadi Siswantoro ${ }^{2}$, Rizky Agung Sukandar ${ }^{3}$ \\ (Received: 01 August 2019 / Revised: 04 September 2019 / Accepted: 29 September 2019)
}

\begin{abstract}
LNG (Liquefied Natural Gas) requires many steps and various types of chemical products. The process also produces waste. The Liquid Incinerator treats waste from LNG process. This unit often experiences damages which causes the plant do not work properly and even a down/trip problems due to the continuous operation and the absence of maintenance program, especially for rotary equipments. This causes environmental pollution because the waste is unprocessed and could have an impact on the increased cost to treat the waste elsewhere. One of approaches to analyze the causes of the damage, the impact and effective treatment for equipment is using Reliability Centered Maintenance (RCM). The RCM method is expected to be able to identify the primary and secondary functions of the system, possible failure function, Failure Mode and Effect Analysis (FMEA), and the maintenance actions on the plant. The FMEA result will be used to determine the proposed maintenance task. Based on the proposed maintenance task, the maintenance interval for each equipment is obtained. After RCM analysis is done on 4 equipments, liquid waste feeding pump (34-G-2), quencher pump (34-G-3), scrubber pump (34-G-4) and air compressor (34-K-4). For 34-G-2 failure mode, requires $78 \%$ preventive maintenance and $22 \%$ corrective maintenance, 34-G-3 requires $87 \%$ preventive maintenance and 13\% corrective maintenance, $34-\mathrm{G}-4$ requires $87 \%$ preventive maintenance and $13 \%$ corrective maintenance and $34-\mathrm{K}-4$ requires $70 \%$ preventive maintenance and $30 \%$ corrective maintenance. Workpackage for each interval is created from every failure mode for each interval for maintenance / inspection.
\end{abstract}

Keywords-FMEA, liquid incinerator, maintenance, RCM, workpackage.

\section{INTRODUCTION}

L NG process from natural gas requires many steps and requires various types of chemical products. The process produces residual waste that contains hazardous and toxic chemical product, if it thrown without process can cause damage and pollute the environment. One of the equipment that commonly used to treat liquid waste is Liquid Incinerator.

Hazardous and toxic waste that produced from LNG manufactured process contains $80 \%$ Methyldiethanolamine (MDEA) and glycol. Methyldiethanolamine is used in natural gas plants to remove carbon dioxide while produce gas streams that contains 0,25 grains of hydrogen sulphide / 100 scf.[1] While glycol is used to eliminate water content on LNG manufactured process.[2] The following are some of the effects of hazards caused by this hazardous and toxic waste :

a. Polluting the soil

b. Causes irritation to the skin and eyes

c. Causes respiratory tract irritation

d. Polluting the water sources

Considering the importance of usability of Liquid Incinerator and its dangers to humans and the environment damage, the government regulates the waste treatment

Dwi Priyanta, Department of Marine Engineering, Institut Teknologi Sepuluh Nopember, Surabaya 60111, Indonesia, Email: priyanta@ne.its.ac.id

Nurhadi Siswantoro, Department of Marine Engineering, Institut Teknologi Sepuluh Nopember, Surabaya 60111, Indonesia, Email: nurhadi@ne.its.ac.id

Rizky Agung Sukandar, Department of Marine Engineering, Institut Teknologi Sepuluh Nopember, Surabaya 60111, Indonesia, Email: rsoekandaragung@gmail.com procedures through Law No. 32 of 2009 concerning Enviromental Protection and Management for every person / company that produces hazardous and toxic waste is obligated to manage the treatment of hazardous and toxic waste. This regulation applies to every person/company that produces hazardous and toxic waste in order to perform maintenance of each waste processing equipment including the Liquid Incinerator.

This regulation is to ensure the environment is not polluted due to the damage of waste treatment equipment. Every company has a program and scheduled maintenance for company assets. But there are times when the implemented of the company's maintenance program considered not optimal so the company is looking for the right and effective maintenance method to reduce the operational and maintenance costs.

The maintenance schedules of rotary equipment for Liquid Incinerator is determined using the Reliability Centered Maintenance (RCM) method based on SAE JA1011 and SAE JA1012. Reliability Centered Maintenance (RCM) is the structured framework of preserving equipment functions, rather than preserving physical asset.[3] In this study, the RCM analysis used was using FMEA and LTA to determining the model of failure and the consequences it caused. Failure mode and effect analysis is a tool that examines potential product or 
process failures, evaluates risk priorities, and helps determine remedial actions to avoid.[4] LTA is a formulated in such a manner to describe how a given type of outcome can occur. [5]

\section{METHOD}

\section{A. Study Case}

The waste that produced in the LNG process contains a hazardous and toxic chemical product such as MDEA and glycol which can damage and pollute the environment if it was thrown. Therefore, an appropriate waste management system is required so that it produces environmentally friendly waste. Liquid Incinerator is used to treat liquid waste to be converted into other forms so as not pollute the environment.

Plant 34 is used to deal with waste problem during the manufacturing process of LNG. Within the time, Liquid Incinerator has suffered a lot of damage and problems that caused the cessation of the waste treatment process. Based on Figure 1, there are 105 damages on Liquid Incinerator starting from February 26, 2013 until July 25, 2018. first in the aircraft industry, and later in military forces, the nuclear power industry, the offshore oil and gas industry, and many others.[9] According to Campbell, if RCM is implemented correctly, it can reduce the number of routine maintenance work by a significant margin.[10] Smith also stated that the benefits and advantages of using RCM were several, and had an impact on operations, safety, logistics, configuration, and administration.[11] The stages in this study are to use seven stages RCM method, they are:

\section{1) Literature Review}

A literature review is a surveys scholarly articles, books and other sources relevant to a particular issue, area of research, or theory, and by so doing, providing a description, summary, and critical evaluation of these works.[12] Literature review is done by reading and summarizing the contents of the book, the thesis related to the final assignment.

2) Data Collection

The next step, is to collect data that will be used as the object of research. Data is divided into 2 categories:[13]

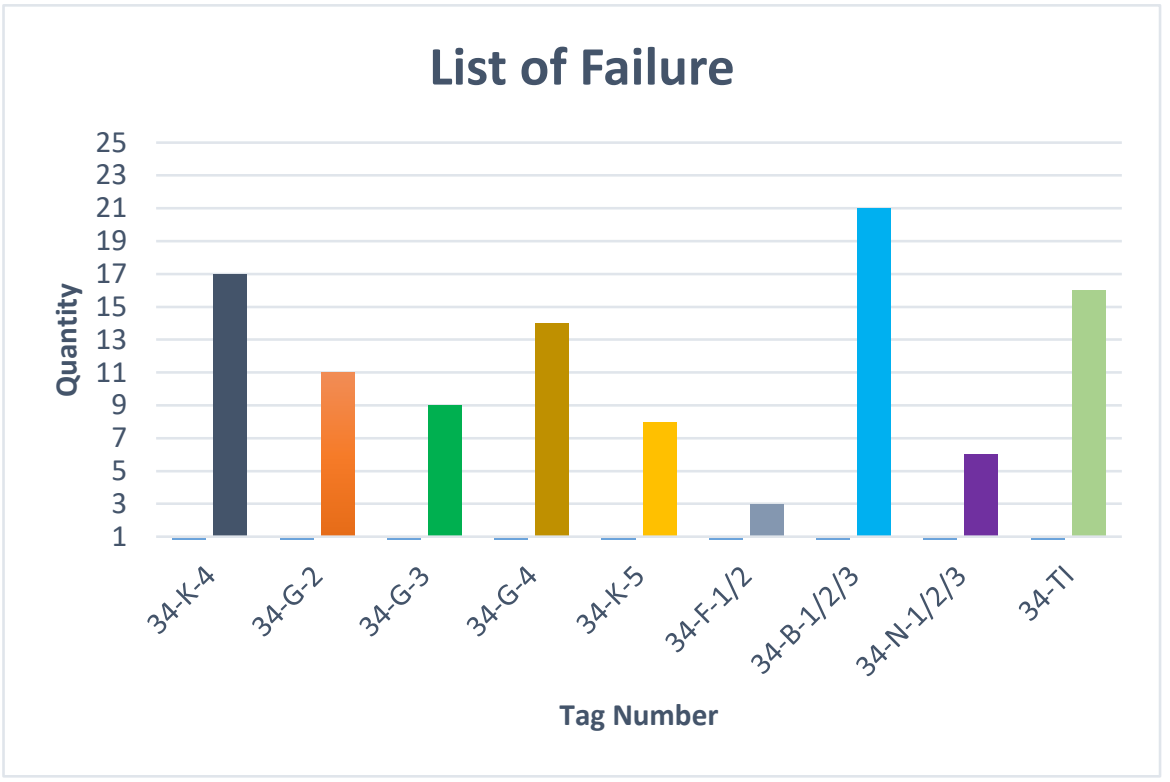

Figure 1. Data for damage amount for each equipment

\section{B. Reliability Centered Maintenance II}

Moubray defines RCM with two events, a process used to determine the maintenance requirements of each physical asset in the context of its operation. The second definition of RCM is a process used to determine what action to take to ensure each physical asset to operate within operator desires in the context of the operation.[6] IEC 60300-3-11 adds the definition of RCM according to Moubray which was then defined as a systematic approach to identifying effective and efficient preventive maintenance for equipment in accordance with procedures and determining maintenance task intervals that must be performed.[7] The strength of the RCM is that it can produce a planned maintenance program that is extraordinarily strong and effective, even in situations where the development team has access to little or no historical data.[8] ausand noted that RCM was implemented with great success for more than 20 years, a. Primary data refers to the first hand data gathered by the researcher himself. Primary data sources include surveys, observations, experiments, questionnaire, personal interview etc.

b. Secondary data means data collected by someone else earlier. Secondary data collection sources are government publications, websites, books, journal articles, internal records etc.

3) System Selection and Definition

Before a decision to perform an RCM analysis at a plant is taken, two questions should be considered.

1. To which systems are an RCM analysis benefical compared with more traditional maintenance planning?

2. At what level of assembly (plant, system, subsystem) should the analysis be conducted? 
All systems may in principle benefit from an RCM analysis. With limited resources, we must, however, make priorities, at least when introducing RCM in a new plant. We should start with the systems that we assume will benefit most from the analysis.[14]

4) System Description and Functional Blocks Functional block diagrams (FBD) are used to describe several functions of a component in an interconnected unity of blocks between the functions of components one to another component to form a unified function of the work system. Inputs and outputs for each variable / component can be connected with other blocks with using connecting lines.[15] The system used in this study is the Liquid Incinerator subsystem.

5) System function \& Functional Failures SAE JA1011 "Evaluation Criteria for RCM Processes" indicates that the failure modes to be considered are:[16]

-Failures that have previously occurred on the equipment or similar machines.

-Possible failures that have not occurred before, but could have serious consequences.

-Failure modes for which preventive maintenance has already been undertaken in order to prevent failure.

6) Failure Mode and Effect Analysis (FMEA)

FMEA is an inductive analysis tool to analyze failure mode and failure effect of the critical components whose failure will lead to undesirable consequences. In the FMEA, all possible failure modes and all the possible consequences of every component also be analyzed and classified with the severity of its failure mode and frequency of occurrence. Based on the system hierarchy tree and the results of the first screening, we can performed the FMEA for the relatively significant items to obtain their function, failure mode and failure effect on the system.[17]

7) Logic Tree Analysis

Logic Tree Analysis (LTA) is a method used to see the impact caused by each failure mode that occurs.[18] This provides a consistent approach to the maintenance of all kinds of equipment.[19]

\section{8) Task Selection}

After finishing step in the RCM process, it's time for task selection. The RCM method uses a logic decision tree, in the form of a flow chart. For each step in the process, a logical question must be answered, yes or no. After ending the selection process, the RCM method will give some proposed maintenance tasks. After that, it's up to the analyst to compare the result from the RCM task selection process with today's maintenance, failure and operational history. From that analysis, some new solutions of proactive maintenance tasks will come out. No scheduled maintenance the no scheduled maintenance is most used when the failure is evident, and does not affect safety or the environment. The components are left in operation until they are either replaced or repaired, in other words they "run-tofailure".[20]

9) Workpackage

A work package is a group of related tasks within a project. Because they look like projects themselves, they are often thought of as subprojects within a larger project. Work packages are the smallest unit of work that a project can be broken down to when creating your Work Breakdown Structure (WBS). Tasks are typically grouped into work packages based on geographical area, engineering discipline, technology, or the time needed to accomplish them.

\section{RESULT}

\section{1) Literature Review}

- Data obtained through interviews:

- Work order

- Common causes of damage

- Historical damage data

- Image documentation of system

- Recommend solutions to overcome and prevent equipment damage

- Impact of damage

- Material losses in case of damage

- Primary and secondary functions on Liquid Incinerator

- Data obtained from manual book, logsheet, and documentation:

- Operational time data

- Amount of waste burned

- Equipment specifications

- Shutdown data

- Data of repair time

- Data of equipment that is often problematic

- PID \& PFD

- Data for performed corrective maintenance

2) System Selection and Definition

The system analyzed is only the system at the Plant 34 Liquid Incinerator with limitation referring to OREDA 2002 and ISO 14224 standard. RCM analysis is carried out at level 6 at the equipment level. The waste liquid feeding pump, quencher pump, scrubber pump and air compressor. The required data is an asset register made based on data from the PFD and the P\&ID of Liquid Incinerator. Figure 2 shows the PFD Liquid Incinerator.

\section{3) Functional Block Diagram}

FBD is required in the RCM process to analyze the functions of each component so that it can determine the type of failure that may occur and the effect it will cause if the component fails. Figure 3 shows the FBD of the Liquid Waste Feeding Pump. 


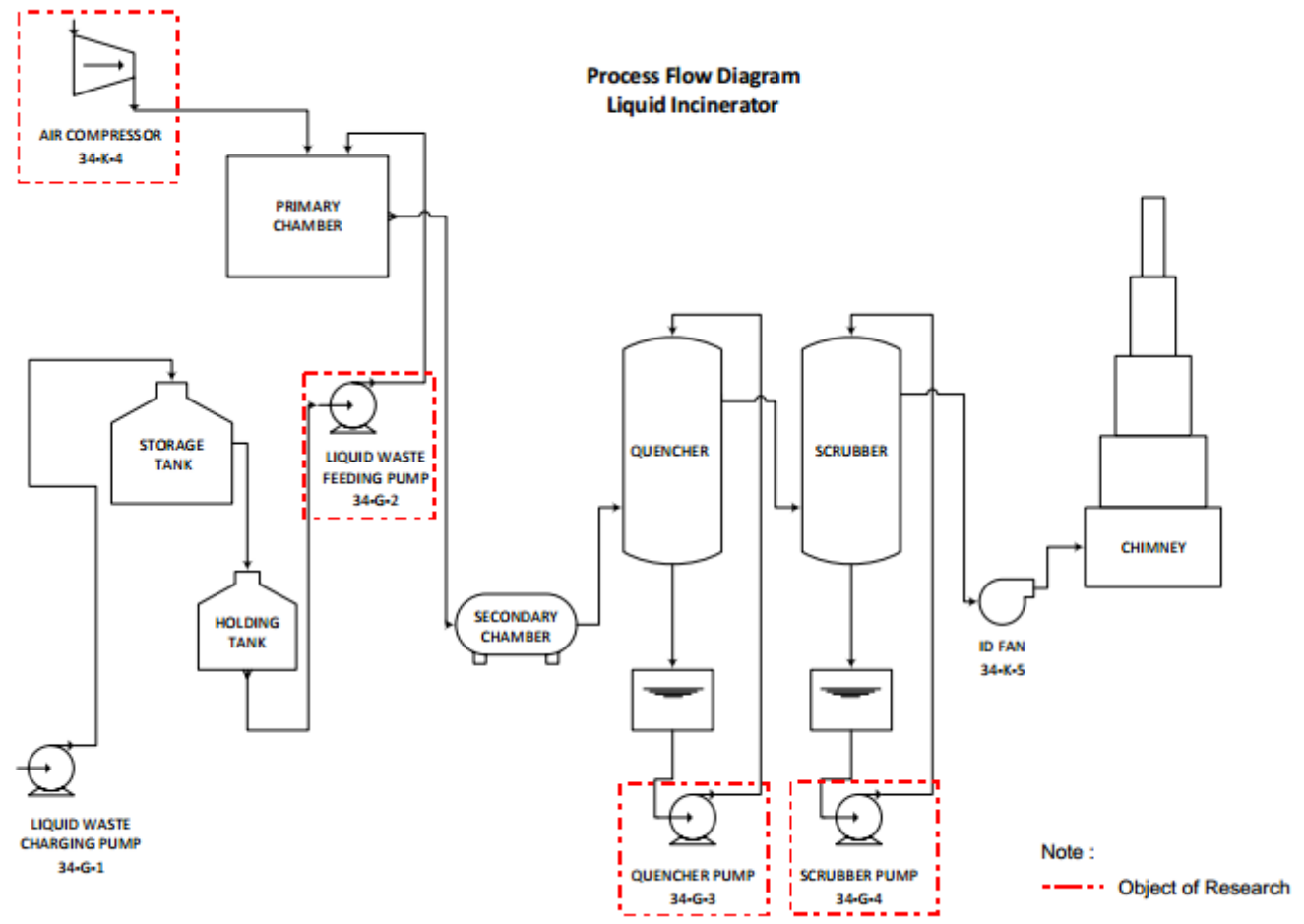

Figure 2. PFD Liquid Incinerator

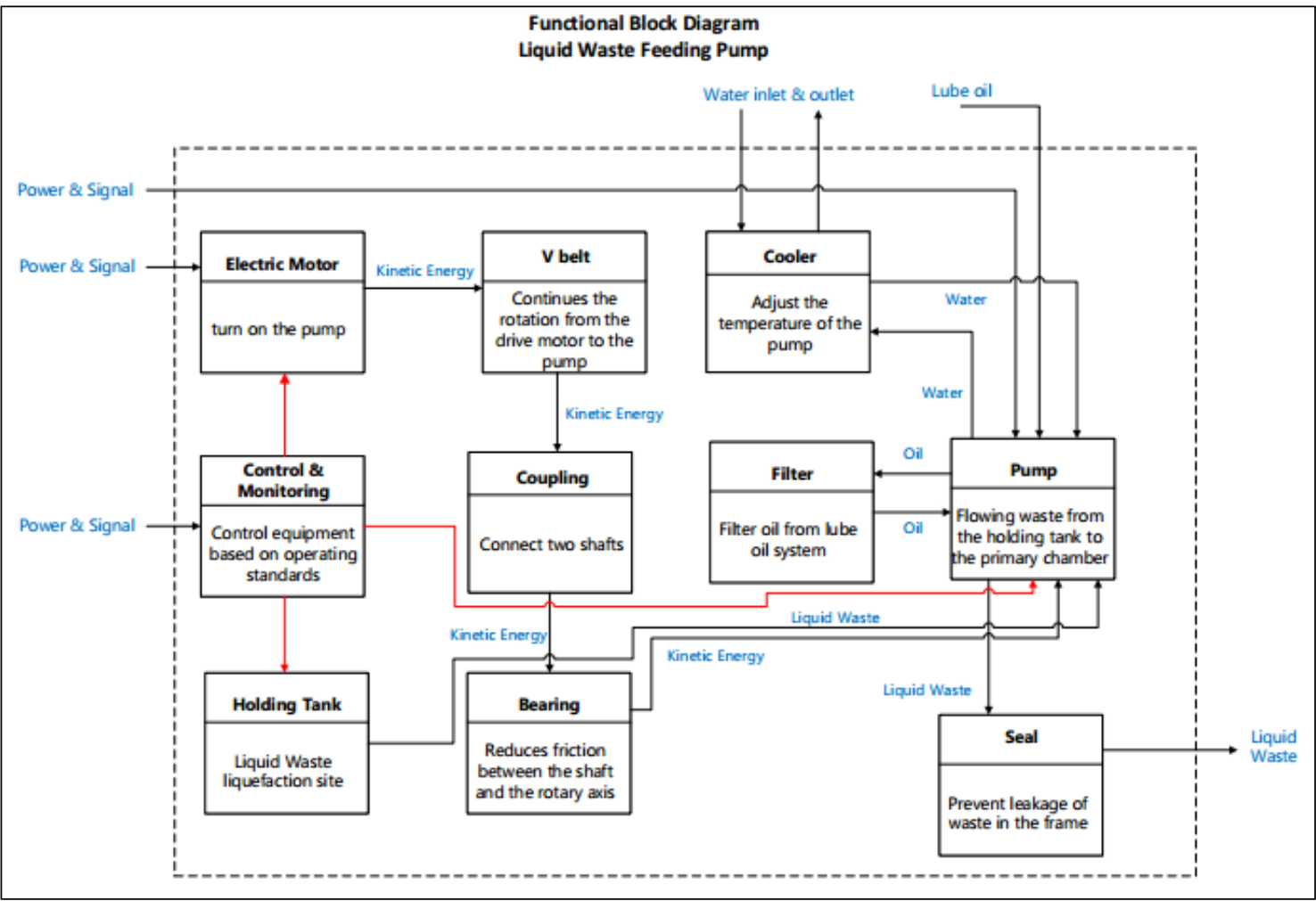

Figure. 3. Functional Block Diagram

4) Failure Modes and Effect Analysis (FMEA)

\section{Function}

To determine the function of each equipment and its components, in this research is using data from the manual Liquid Incinerator book, interviews with operators and journals about the function of the components in the pump at the Liquid Incinerator.

\section{Function Failure}

In this paper, there are two parameters that must be met in system functions. The first is the equipment moves the working fluid, and the second is the process of working fluid displacement that has certain performance specifications. If one of the two parameters is not met, a malfunction occurs.

\section{Failure Mode}


To determine the cause of failure of an equipment, this research refers to the manual book, journal and work order.

\section{Failure Effects}

The effects of each failure mode, this research used the FBD and the manual book to know the effect it will have.

\section{5) Probability Rating}

The probability rating value is obtained from the company. The following Table $\mathbf{1}$ is the probability used in this research.

6) Consequences Analysis environment, safety and operational. Figure 7 shows the template used for task selection.

9) Purposed Task

The results of task selection analyze on 4 equipment, most of the equipment are scheduled on-condition tasks. Figure $\mathbf{8}$ shows the percentage of tasks from the 4 equipment.

10) Initial Interval

In determine the inspection / repair interval, this research refers to the manual book, journal and data maintenance that has been done.

TABLE 1.

PROBABILITY RATING

\begin{tabular}{cccl}
\hline No & Definition & Indeks & Criteria \\
\hline 1 & Very Likely (VL) & 16 & Frequently happens or has happened more than once in Badak LNG \\
2 & Likely (L) & 8 & Has happened once in Badak LNG \\
3 & Possible (P) & Has happened several times in the petroleum and gas industry \\
4 & Unlikely (U) & 2 & $\begin{array}{l}\text { Heard of in the petroleum and gas industry or experienced at least once in the } \\
\text { petroleum and gas industry }\end{array}$ \\
5 & Very Unlikely (VU) & 1 & Never heard of in the petroleum and gas industry
\end{tabular}

The consequence value is used 9 consequences. Includes environment, material, production loss, reputation, law, media, occupational injury, occupational illness, and occupational efficiency costs.

7) Component Critical Level

After the probability rating and consequences is determined, then determine the two values on the risk matrix as shown in Figure 4. This company categorize criticality based on probability and consequence into three levels namely Low, Medium, High. Table 2 shows the conversion from multiplication between probability and consequence into the critical rating of the

\section{1) Workpackage}

Workpackage is made per component which consists of maintenance intervals, maintenance operator and maintenance actions to be taken. This research refers to the manual book and implemented maintenance in compiling this workpackage.Figure $\mathbf{9}$ is an example of workpackage on the 34-G-2 pump belt.

TABLE 2.

CONVERSION OF RISK RATING TO COMPONENT CRITICAL RATING

\begin{tabular}{cccc}
\hline Risk Index & Risk Rating & Critical Index & Critical Rating \\
\hline $1-4$ & Low & L & Low \\
$8-32$ & Medium & M & Medium \\
$64-256$ & High & H & High \\
\hline
\end{tabular}

component. Then the analysis and calculations is performed using a template according to Figure 5. The scheduled maintenance only performed for medium and high maintenance, while the low risk level there is no scheduleded maintenance. Figure 6 shows an example of the critical level at pump 34-G-2.

\section{8) Logic Tree Analysis}

Then, the task selection is performed for failure modes that have medium and high risk. Determination of task selection in each failure mode considers evident / hidden failure, health / 
International Journal of Marine Engineering Innovation and Research, Vol. 4(3), Sept. 2019. 191-198 (pISSN: 0853-4098, eISSN: 2548-1479)

\begin{tabular}{|c|c|c|c|c|c|c|}
\hline Probability/Likelihood & Weight & \multicolumn{5}{|c|}{ Risk $=($ Probability or Likelihood $) X$ (Severity of Consequence $)$} \\
\hline Very Likely (VL) & 16 & M & $\mathrm{M}$ & $\mathrm{H}$ & $\mathrm{H}$ & $\mathrm{H}$ \\
\hline Likely (L) & 8 & $\mathrm{M}$ & $\mathrm{M}$ & $\mathrm{M}$ & $\mathrm{H}$ & $\mathrm{H}$ \\
\hline Possible (P) & 4 & $\mathrm{~L}$ & M & M & M & $\mathrm{H}$ \\
\hline Unlikely (U) & 2 & $\mathrm{~L}$ & $\mathrm{~L}$ & $\mathrm{M}$ & $\mathrm{M}$ & $\mathrm{M}$ \\
\hline Very Unlikely (VU) & 1 & $\mathrm{~L}$ & $\mathrm{~L}$ & L & $M$ & $M$ \\
\hline \multicolumn{2}{|c|}{ Severity of Consequence } & Minor (Mn) & Moderate (Md) & Serious (Sr) & Major (Mj) & Catastrophic (Ct) \\
\hline \multicolumn{2}{|l|}{ Weight } & 1 & 2 & 4 & 8 & 16 \\
\hline
\end{tabular}

Figure. 4. Risk Matriks 5 x 5

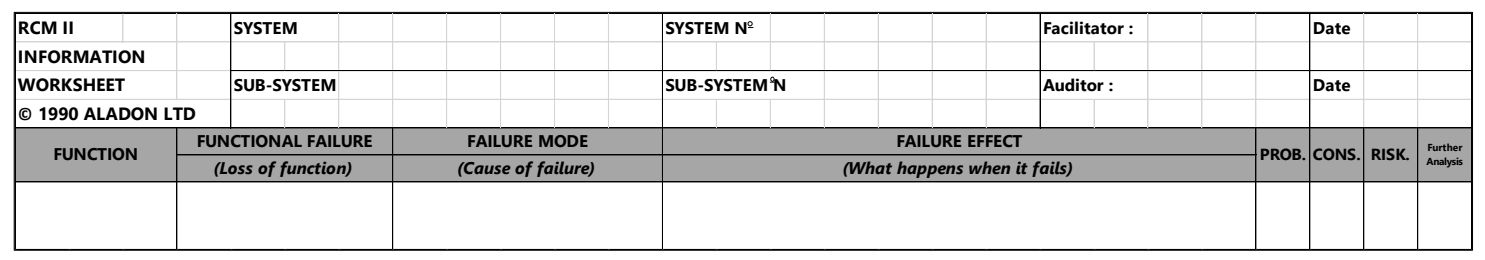

Figure. 5. Template FMEA

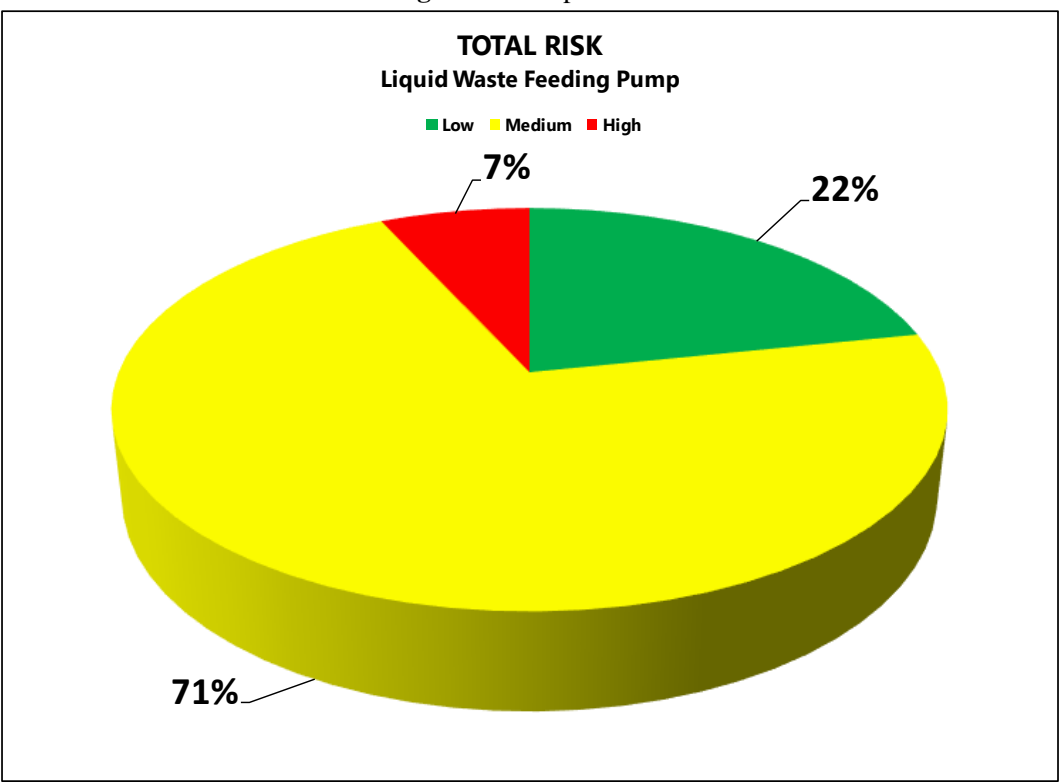

Figure. 6. The critical level of the 34-G-2 pump

\begin{tabular}{|c|c|c|c|c|c|c|c|c|c|c|c|c|c|c|c|c|c|}
\hline \multirow{2}{*}{\multicolumn{4}{|c|}{$\begin{array}{l}\text { RCM II } \\
\text { INFORMATION } \\
\text { WORKSHEET } \\
\text { @ } 1990 \text { ALADON LTD }\end{array}$}} & \multicolumn{8}{|c|}{ SYSTEM } & & \multirow{2}{*}{\begin{tabular}{|c|} 
SYSTEM N \\
34-F-3 \\
SUB-SYSTEM N \\
34-G-4 \\
\end{tabular}} & \multirow{2}{*}{\begin{tabular}{|l|} 
Facilitator: \\
Auditor:
\end{tabular}} & \multirow{2}{*}{\begin{tabular}{|l|} 
Date \\
Date
\end{tabular}} & \multirow{2}{*}{ 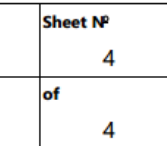 } & \multirow{2}{*}{ Form 06} \\
\hline & & & & \multicolumn{9}{|c|}{\begin{tabular}{|l} 
SUB-SYSTEM \\
Scrubber Pump
\end{tabular}} & & & & & \\
\hline \multirow{3}{*}{\multicolumn{3}{|c|}{$\begin{array}{l}\text { Information } \\
\text { reference }\end{array}$}} & \multirow{3}{*}{\multicolumn{4}{|c|}{$\begin{array}{l}\text { Consequence } \\
\text { Evaluation }\end{array}$}} & H1 & H2 & H3 & \multirow{3}{*}{\multicolumn{3}{|c|}{$\begin{array}{l}\text { Default } \\
\text { action }\end{array}$}} & \multirow{3}{*}{\multicolumn{2}{|c|}{ Proposed task }} & & \multirow{3}{*}{ Initial Interval } & \multirow{3}{*}{$\begin{array}{c}\text { Can be done } \\
\text { by }\end{array}$} \\
\hline & & & & & & & S1 & S2 & S3 & & & & & & & & \\
\hline & & & & & & & 01 & 02 & 03 & & & & & & & & \\
\hline 1 & A & 2 & $\mathrm{Y}$ & $\mathrm{N}$ & $\mathrm{Y}$ & & $\mathrm{Y}$ & & & & & & \multicolumn{3}{|c|}{ System control : Scheduled on-condition task } & 2 weeks & Mechanic \\
\hline 1 & $\mathrm{~A}$ & 3 & $\mathrm{Y}$ & $\mathrm{N}$ & $\mathrm{Y}$ & & $\mathrm{Y}$ & & & & & & \multicolumn{3}{|c|}{ Valve : Scheduled on-condition task } & 3 months & Mechanic \\
\hline 1 & $\mathrm{~A}$ & 4 & $\mathrm{Y}$ & $\mathrm{N}$ & $\mathrm{Y}$ & & $\mathrm{Y}$ & & & & & & \multicolumn{3}{|c|}{ Shaft : Scheduled on-condition task } & 6 months & Mechanic \\
\hline 1 & A & 5 & $Y$ & $\mathrm{~N}$ & $\mathrm{~N}$ & $Y$ & $\mathrm{~N}$ & $\mathrm{~N}$ & $\mathrm{~N}$ & & & & \multicolumn{3}{|c|}{ No scheduled maintenance } & - & - \\
\hline
\end{tabular}

Figure. 7. Template Task Selection 


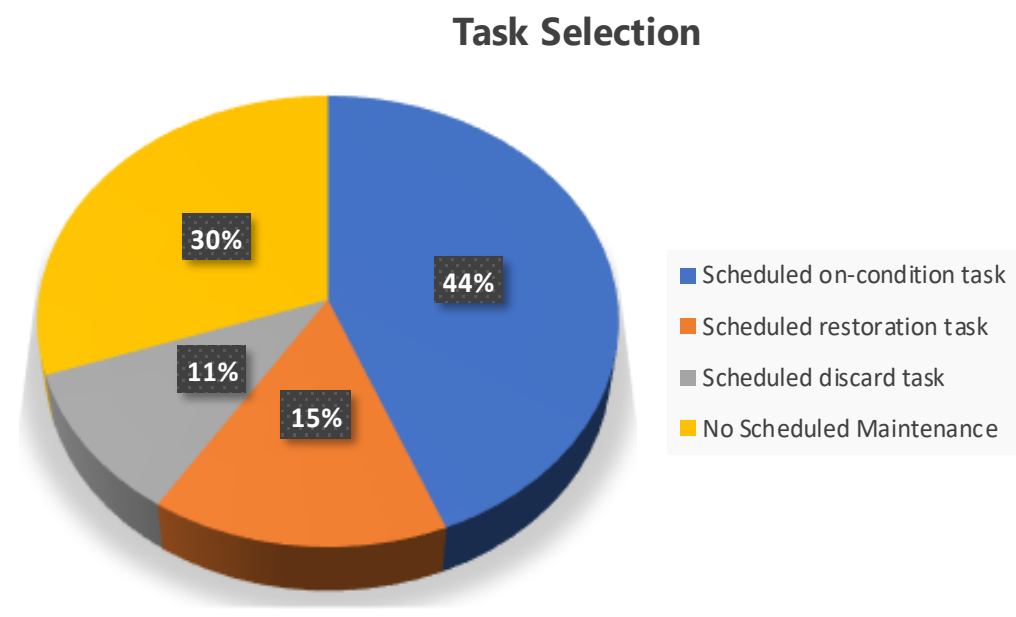

Figure. 8. Task Selection

\begin{tabular}{|l|}
\hline \multicolumn{2}{|c|}{ Maintenance Schedule } \\
\hline \multicolumn{2}{|c|}{ BELT LIQUID WASTE FEEDING PUMP (34-G-2) } \\
\hline \multicolumn{2}{|c|}{ Interval } \\
\hline \multicolumn{1}{|c|}{ Months } \\
Following these recommended steps should help operators reduce problems with \\
V-belt drives. Here is a brief check list: \\
1.Test to make sure that the power is off.Lock the control box and tag it. \\
2. Lock down all machine components, and put them in a safe or neutral position. \\
3. Remove the guard and inspect it for damage. \\
4. Inspect the belt for excessive wear or damage, and replace as needed. \\
5. Inspect the sheaves or sprockets for excessive wear or damage, and replace if \\
worn (always wear gloves when inspecting metal parts to prevent cuts). \\
6. Inspect other drive components (such as the bearings, shafts, etc). \\
7. Inspect the static conductive grounding system, if present. \\
8. Check the belt tension and adjust, as needed. \\
9. Recheck the sheave or sprocket alignment and adjust, if necessary. \\
10. Repeat the previous two steps as needed until tension and alignment are \\
properly adjusted. \\
11. Reinstall the belt guard. \\
12. Turn on the power, and restart the drive.
\end{tabular}

Figure. 9. Workpackage of Pump Belt components 34-G-2

\section{CONCLUSION}

Based on the analysis above, the conclusions are the maintenance of waste liquid feeding, quencher pump, scrubber pump and air compressor only describe preventive maintenance in general. After RCM analysis, preventive maintenance is performed in detail on each component and more precisely based on the level of risk in workpackage form. For failure modes that have a high risk, the interval of preventive maintenance performed every 1 until 7 days. So based on the RCM II John Moubray book, the maintenance is included to the standard operating procedure of the plant. For the interval preventive, the longest interval is performed on the relief valve with a 3 years inspection interval.
The suggestions based on the analysis above, are:

1. RCM analysis can be performed up to the level of parts to obtain more detailed analysis.

2. The calculation of the cost analysis can be performed as a consideration in RCM analysis to get more effective and efficient result.

\section{REFERENCES}

[1] Methyldiethanolamine (MDEA). Technical Bulletin Huntsman Corporation Business Offices. Woodloch Forest Dr. The Woodlands, United States

[2] Hasan, Md. Mehedi, et al. 2016. Natural Gas Dehydration Process in Bangladesh. International Conference on Petroleum Engineering 2016 (ICPE-2016). Dhaka-1000, Bangladesh

[3] Tarar, Mariam Altaf. 2014. Study Reliability Centered Maintenance (RCM) of Rotating Equipment through 
Predictive Maintenance. 2nd International Conference on Research in Science, Engineering and Technology (ICRSET'2014), March 21-22, 2014 Dubai (UAE)

[4] Afefy, Islam H. 2010. Reliability-Centered Maintenance Methodology and Application:A Case Study. Industrial Engineering Department, Faculty of Engineering, Fayoum University, Al Fayyum, Egypt. Engineering, 2010, 2, 863873

[5] Lopez, A David \& Slyke William J Van. 1977. Logic Tree Analysis for Decision Making.OMEGA, The Int. Jl of Mgmt Sci, Vol. 5, No. 5,1977. Pergamon Press. Printed in Great Britain

[6] Moubray, J. 1997. Reliability-Centered Maintenance II, $2^{\text {nd }}$ edition, Butterworth Heinemann, Oxford

[7] IEC 60300-3-11, 1999. Application Guide RCM, International Electro-Technical Commission, Geneva.

[8] Sutton, I.S. 1995. Integrated Management System Improvement plant Reliability, Journal of Hydrocarbon Processing, Vol. 74 No.1, pp 63-66.

[9] Rausand M. 1998. Reliability Centred Maintenance, Journal of Reliability Engineering and System Safety, Vol. 60 No. 2, pp 121-132.

[10] Campbell J.D. 1999.The Reliability Handbook - Plant engineering and maintenance,Volume 23, Clifford/ Elliot Publications.

[11] Smith, A.M. 1993. Reliability Centred Maintenance, McGraw Hill Inc, New York.

[12] Ramdhani, Abdullah, Ramdhani, Muhammad Ali \& Amin, Abdusy Syakur.2014. Writing a Literature Review Research Paper : A step-by-step approach. International Journal of Basic and Applied Science, Vol. 03, No. 01, July 2014, pp. 47-56

[13] Ajayi, Oluwatosin Victor. 2017. Distinguish between primary sources of data and secondary sources of data. Department of Curriculum and Teaching Faculty of Education. Benue State University, Makurdi.

[14] Rausand, Marvin.1998.Reliability Centered Maintenance. Elsevier Science Limited. Rriiabiliry Engineering and System Safety 60 (1998) 12 I- 132

[15] Hidayat, Rachmad, Ansori, Nachnul \& Imron, Ali. 2010. Perencanaan Kegiatan Maintenance Dengan Metode Reliability Centered Maintenance II. MAKARA, TEKNOLOGI, VOL. 14, NO. 1, APRIL 2010: 7-14

[16] Fore,S. \& Msipha, A. 2010. Preventive Maintenance Using Reliability Centred Maintenance (RCM): A Case Study Of A Ferrochrome Manufacturing Company. South African Journal of Industrial Engineering May 2010 Vol 21(1): 207235

[17] Tang,Yang, et al.2016.A framework for identification of maintenance significant items in reliability centered maintenance.ELSEVIER. Y. Tang et al. / Energy xxx (2016) $1 \mathrm{e} 9$

[18] Susanto, Agustinus Dwi. \& Azwir, Hery Hamdi. 2018. Perencanaan Perawatan Pada Unit Kompresor Tipe Screw Dengan Metode RCM di Industri Otomotif, Jurnal Ilmiah Teknik Industri

[19] Rose, Al. 2002. Reliability Centered Maintenance. High Technology Solutions for the Procedures, Distributors and Users of Electric Power. Technical Bulletin-014

[20] Naik, B. Devaraj \& Soni, Pradeep Kumar. 2016. Research Review on Reliability Centred Maintenance. International Journal of Innovative Research in Science, Engineering and Technology. Vol. 5, Issue 6, June 2016 